\title{
The sensitivity of an eddy-resolving model to the surface thermal boundary conditions
}

\author{
Weimin $\mathrm{Xu}$ \\ Climate Research Division, Scripps Institute of Oceanography, La Jolla, California \\ Richard J. Greatbatch \\ Department of Physics, Memorial University of Newfoundland, St. John's, Canada
}

Charles A. Lin

Department of Atmospheric and Oceanic Sciences and Center for Climate and Global Change Research, McGill University, Montreal, Quebec, Canada

\begin{abstract}
We compare the effect of using four different formulations for the surface thermal boundary condition on a primitive equation eddy-resolving model. The first formulation is the conventional restoring boundary condition. This relaxes the surface temperature of the model to a specified "restoring temperature" on a timescale of 30 to 60 days. The second formulation calculates the surface heat flux interactively by coupling the ocean model to a simple atmospheric model with an effective restoring time of several hundred days. The third formulation (Rahmstorf and Willebrand, 1995) (RW0) is a simplified energy balance model without atmospheric heat transport. The fourth formulation (Rahmstorf and Willebrand, 1995) (RW1) is a linearized energy balance model with atmospheric heat transport parameterized as a diffusion term. The biggest impact is on the vertical structure of the temperature variance. Under the restoring condition the maxima in this variance always occur beneath the surface. Under the other three boundary conditions, maxima are found at the surface and/or subsurface levels, depending on geographical location and in closer agreement with observations. There is also an increase in the magnitude and eastward extension of both the eddy and mean kinetic energy at midlatitudes and in the subpolar gyre region with the use of less constraining surface boundary conditions. We suggest that the use of a conventional restoring surface boundary condition acts to suppress mesoscale variability in eddy-resolving models. The northward heat transport is also increased by using the RW0 and RW1 formulations. The main reason for the enhancement of eddy variability and northward heat transport using the RW0 and RW1 surface boundary conditions is the release of the mean state.
\end{abstract}

\section{Introduction}

Ocean models are forced at the surface by momentum and buoyancy sources from the atmosphere through the wind stress, heat, and freshwater fluxes, respectively. Most eddy-modeling studies have been carried out using a restoring condition on the surface temperature [e.g., Semtner and Mintz, 1977; Robinson et al., 1977; Cox, 1985; Bryan and Holland, 1989; Böning, 1989; Böning and Budich, 1992; Semtner and Chervin, 1988, 1992]; although some studies allow for a time and space dependent restoring coefficient [Bryan and Holland, 1989]. With the restoring condition on surface temperature the

Copyright 1995 by the American Geophysical Union.

Paper number 95JC01590.

0148-0227/95/95JC-01590\$05.00 model top level temperature is restored to a specified "restoring" temperature on a timescale of 30 to 60 days. This condition has been justified by a linearization of the heat budget terms about the air temperature at the air-sea interface [Haney, 1971], in which case the restoring temperature is referred to as the "equivalent atmospheric temperature." Han [1984] gives empirical formulas to compute the spatially dependent distributions of the relaxation coefficient and the equivalent atmospheric temperature.

In this study we examine some alternative treatments of the surface thermal boundary condition through the use of simple energy balance models of the atmosphere. This is of potential significance to not only eddy simulation, but also to climate studies, as the surface heat flux is important for the maintenance of midlatitude free jets [Huang, 1990; Ezer and Mellor, 1992] and thermohaline circulation [Rahmstorf and Willebrand, 1995] 
(hereinafter referred to as RW) [Greatbatch and Zhang, 1995].

A simple way to include a thermally interactive atmosphere is to assume that the atmosphere has zero heat capacity, i.e., to assume that the atmosphere is always in a steady balance with the ocean. This is based on the observation that the heat capacity of the atmosphere is much less than that of the ocean mixed layer [Dickinson, 1981]. Schopf [1983] noted that the air-sea temperature difference in the tropics rarely exceeds $1^{\circ} \mathrm{C}$, even in areas with significant upwelling of cold water. He suggested the use of a zero heat capacity atmosphere model that exhibits this behavior. The reason the surface air temperature closely follows the sea surface temperature (SST) in the Schopf model is that the air-sea coupling is much stronger than the radiative relaxation to space. Deser and Blackmon [1993] show that surface air temperature is also closely tied to sea surface temperature at midlatitudes. Recently, Zhang et al. [1993] coupled the Schopf model to a planetary geostrophic basin scale ocean model at noneddyresolving horizontal resolution to reexamine the polar halocline catastrophe. They noted that, in reality, the atmospheric boundary condition seen by the ocean lies somewhere in between the two extremes of the restoring condition and the Schopf model.

Another simple way to include an interactive atmosphere is to use the energy balance model given by RW. This model includes an additional term as scale selective divergence of the atmospheric heat transport.

A consideration of the surface temperature boundary condition relevant to eddy simulation is the possible overrestrictive nature of the restoring condition on the simulated surface temperature [Zhang et al., 1993; RW; Marotzke, 1994]. The strict constraint of this surface boundary condition effectively removes eddy available potential energy near the sea surface and prevents the concentration of isotherms. This could reduce the midlatitude flow and damp baroclinic instability. It is thus of great interest to examine the effect of relaxing the restoring constraint on eddy-resolving models.

The plan of this paper is as follows. Section 2 presents the model equations and boundary conditions. Section 3 describes the surface thermal boundary conditions used in this study and the modeling strategy. Sections 4 and 5 compare the results from the four different boundary conditions for horizontal and vertical flow fields, respectively. Section 6 gives a brief discussion on the northward heat transport. Conclusions are given in section 7 .

\section{Model}

\subsection{Model Equations}

The model uses the primitive equations of motion with the Boussinesq and hydrostatic approximations. The notation used is standard, and the notation section contains a list of symbols and their explanation. The governing equations are the conservation of horizontal momentum, (1) and (2); the conservation of (potential) temperature, (3); the hydrostatic approximation, (4); the incompressibility condition, (5); and equation of state, (6).

$$
\begin{aligned}
& \frac{\partial u}{\partial t}+L(u)=-\frac{1}{\rho_{0}} \frac{\partial p}{\partial x}+f v \\
&+\frac{\partial}{\partial z}\left(A_{M V} \frac{\partial u}{\partial z}\right)+F_{x}+\epsilon \lambda \frac{\partial D}{\partial x} \\
& \frac{\partial v}{\partial t}+L(v)=-\frac{1}{\rho_{0}} \frac{\partial p}{\partial y}-f u \\
&+ \frac{\partial}{\partial z}\left(A_{M V} \frac{\partial v}{\partial z}\right)+F_{y}+\epsilon \lambda \frac{\partial D}{\partial y} \\
& \frac{\partial T}{\partial t}+L(T)=\frac{\partial}{\partial z}\left(A_{H V} \frac{\partial T}{\partial z}\right)+F_{T} \\
& p_{z}=-\rho g \\
& \nabla \cdot \vec{V}=0 \\
& \rho=\rho_{0}\left(1+\alpha\left(T_{0}-T\right)\right) .
\end{aligned}
$$

Here $L()$ is the advection operator, which is given by

$$
L(\sigma)=\frac{\partial u \sigma}{\partial x}+\frac{\partial v \sigma}{\partial y}+\frac{\partial w \sigma}{\partial z} .
$$

$F_{x}, F_{y}$ are the horizontal viscosity terms in the $x$ and $y$ directions, respectively. $F_{T}$ is the horizontal diffusion term for temperature. The Laplacian operator is

Then

$$
\Delta \mu=\frac{\partial}{\partial x}\left(\frac{\partial \mu}{\partial x}\right)+\frac{\partial}{\partial y}\left(\frac{\partial \mu}{\partial y}\right) .
$$

$$
\begin{aligned}
& F_{x}=A_{M H} \Delta^{k} u \\
& F_{y}=A_{M H} \Delta^{k} v \\
& F_{T}=A_{H H} \Delta^{k} T
\end{aligned}
$$

where $k=1$ for Laplacian diffusion in the coarse resolution regime and $k=2$ for biharmonic diffusion in the eddy-resolving regime. The latter is used to reduce the dissipation effects of Laplacian diffusion [Holland, 1978; Semtner and Mintz, 1977; Cox, 1985; Xu, 1994]. $A_{M V}$ and $A_{H V}$ are the vertical viscosity and diffusivity, respectively, and $A_{M H}$ and $A_{H H}$ are the horizontal viscosity and diffusivity, respectively.

The model is formulated on the Arakawa $\mathrm{C}$ grid, which has been shown to be more accurate than the B grid in simulating geostrophic adjustment [Arakawa and Lamb, 1977; Batteen and Han, 1981; Bryan, 1989] and convective adjustment [ $X u$ and Lin, 1993]. An additional friction term is added in the horizontal momentum equations; $\epsilon$ is a multiplier with value 0 or 1 , and $\lambda$ is a diffusivity coefficient which operates on the horizontal divergence D [Sadourny, 1975; Robert, 1981]. This friction term is added because $\mathrm{C}$ grid numerical models can produce a noisy vertical velocity field when the horizontal grid size is larger than the Rossby radius of 
Table 1. The Vertical Coordinate of the Model and the Depth of Each Level

\begin{tabular}{ccc}
\hline Level & $\begin{array}{c}\text { Level Depth, } \\
\text { m }\end{array}$ & $\begin{array}{c}\text { Level Thickness, } \\
\text { m }\end{array}$ \\
\hline 1 & 25 & 50 \\
2 & 75 & 50 \\
3 & 150 & 100 \\
4 & 250 & 100 \\
5 & 400 & 200 \\
6 & 600 & 200 \\
7 & 850 & 300 \\
8 & 1200 & 400 \\
9 & 1600 & 400 \\
10 & 2000 & 400 \\
11 & 2400 & 400 \\
12 & 2800 & 400 \\
13 & 3250 & 500 \\
14 & 3750 & 500 \\
\hline
\end{tabular}

deformation [Batteen and Han, 1981]. The divergence dissipation term can effectively eliminate this noise in a coarse resolution model, keeping other fields relatively unaffected $[X u, 1994]$. For eddy-resolving models with $30-\mathrm{km}$ horizontal resolution the divergence dissipation is only needed in part of the subpolar gyre, where the Rossby radius of deformation is smaller than $30 \mathrm{~km}$ due to both weak stratification and larger Coriolis parameter. Therefore the divergence dissipation is used only within $800 \mathrm{~km}$ of the northern boundary, with $\lambda$ $=2 \times 10^{8} \mathrm{~cm}^{2} \mathrm{~s}^{-1}$.

The model is based on the $\beta$ plane, with a rectangular domain centered at $40^{\circ} \mathrm{N}$, as an idealized version of the North Atlantic. The horizontal extent of the domain is $4000 \mathrm{~km}$ and $4800 \mathrm{~km}$ in the zonal and meridional directions, respectively. The depth is $4 \mathrm{~km}$.

\subsection{Boundary Conditions}

The horizontal boundaries are insulated, and a no-slip boundary condition is used. At the southern boundary, a free-slip condition is used to minimize the effect of the artificial solid wall.
The top boundary is rigid, with a specified wind stress. The bottom is insulated, with Rayleigh friction included.

At the top, $z=0$, we then have

$$
\begin{aligned}
A_{M V}\left(u_{z}, v_{z}\right) & =\left(\tau_{x}, \tau_{y}\right) \\
w & =0
\end{aligned}
$$

where $\tau_{x}$ and $\tau_{y}$ are zonal and meridional wind stress, respectively.

At the bottom, $z=-H$, we have

$$
\begin{aligned}
A_{M V}\left(u_{z}, v_{z}\right) & =\left(\tau_{x}^{B}, \tau_{y}^{B}\right) \\
& =(-r u,-r v) \\
A_{H V} T_{z} & =0 \\
w & =0
\end{aligned}
$$

where $r=10^{-7} \mathrm{~s}^{-1}$ is the Rayleigh bottom friction coefficient.

For the biharmonic frictional parameterization an additional lateral boundary condition is needed for both

Table 2. Summary of the Dissipative Parameters Used in the Numerical Experiments

\begin{tabular}{cccccccc}
\hline Case & SBC & $\begin{array}{c}\tau_{R}, \\
\text { days }\end{array}$ & $\begin{array}{c}A_{M H}, \\
\mathrm{~cm}^{4} \mathrm{~s}^{-1}\end{array}$ & $\begin{array}{c}A_{M V}, \\
\mathrm{~cm}^{2} \mathrm{~s}^{-1}\end{array}$ & $\begin{array}{c}A_{H H}, \\
\mathrm{~cm}^{4} \mathrm{~s}^{-1}\end{array}$ & $\begin{array}{c}A_{H V}, \\
\mathrm{~cm}^{2} \mathrm{~s}^{-1}\end{array}$ & $\begin{array}{c}\mu, \\
\mathrm{cm}^{2} \mathrm{~s}^{-1}\end{array}$ \\
\hline 1 & RS & 30 & $-2 \times 10^{18}$ & 10 & $-10^{19}$ & 0.5 & 0 \\
2 & SM & 360 & $-2 \times 10^{18}$ & 10 & $-10^{19}$ & 0.5 & 0 \\
3 & RW0 & 360 & $-2 \times 10^{18}$ & 10 & $-10^{19}$ & 0.5 & 0 \\
4 & RW1 & 360 & $-2 \times 10^{18}$ & 10 & $-10^{19}$ & 0.5 & $5 \times 10^{6}$ \\
\hline
\end{tabular}

Horizontal resolution $\Delta x=\Delta y=30 \mathrm{~km}$. SBC indicates surface thermal boundary condition; RS restoring boundary condition; SM, Schopf [1983] model; RWO, Rahmstorf and Willebrand [1995] model without atmospheric heat transport; RW1, Rahmstorf and Willebrand model [1995]; $\tau_{B}$, restoring time constant; $A_{M H}$ and $A_{M V}$, horizontal and vertical viscosity; $A_{H H}$ and $A_{H V}$, horizontal and vertical diffusivity; and $\mu$, constant of temperature diffusion in the energy balance model. 

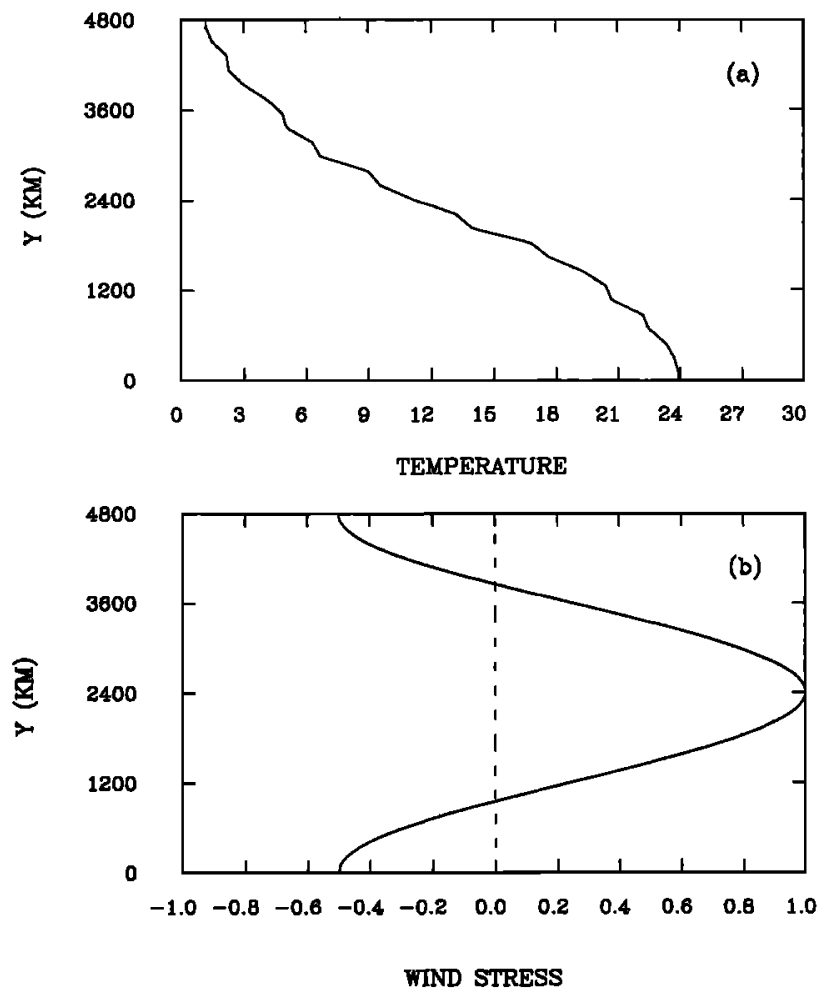

Figure 1. The latitudinal distribution of the (a) equivalent atmospheric temperature (degrees Celsius) and (b) zonal wind stress (dynes per cubic centimeter) used as surface forcings. There is no variation with longitude.

momentum and temperature. We set all the normal gradients of the Laplacian operator to zero in this case [Semtner and Mintz, 1977; Cox, 1985; Xu, 1994].

The model vertical resolution is shown in Table 1 , and the model parameters are given in Table 2. Both wind stress and equivalent atmospheric temperature used for the surface-restoring boundary condition are functions of $y$ (latitude) only and are shown in Figure 1 . The wind stress is a typical double gyre used for idealised studies. The equivalent atmospheric temperature was obtained from Levitus [1982] climatology by Gough and Lin [1992].

\section{Surface Thermal Boundary Conditions}

\subsection{Restoring Condition (RS)}

The RS condition [Haney, 1971] is evaluated at the surface, $z=0$, as follows,

$$
\begin{aligned}
A_{H V} T_{z} & =\frac{K}{\rho_{o} C}\left(T_{A}-T_{1}\right) \\
& =\frac{\Delta z_{1}\left(T_{A}-T_{1}\right)}{\tau_{R 1}}
\end{aligned}
$$

where $T_{A}$ is the equivalent atmospheric equilibrium temperature shown in Figure $1 \mathrm{a}, T_{1}$ is the top model level temperature, $K$ is the heat exchange coefficient across the air-sea interface, $C$ is the specific heat of seawater at constant pressure, $\Delta z_{1}$ is the depth of top model level $(50 \mathrm{~m}), C_{o}=\rho_{o} C \Delta z_{1}$ is the heat capacity of the ocean mixed layer, and $\tau_{R 1}=C_{o} / K$ is the restoring time constant (30 days). This boundary condition assumes a constant atmospheric temperature and is applicable for spin-up experiments to get steady state solutions, but it is not strictly applicable for studies in which sea surface temperature is time dependent [Marotzke, 1994].

The model used in the present study was first run to a statistical steady state using a $40-\mathrm{km}$ resolution with an RS condition on temperature. The variables were then interpolated to a $30-\mathrm{km}$ grid and the model run for a further 10 years to bring it to statistical equilibrium. The mean sea surface temperature $\overline{T_{1}}$ and surface heat flux (FLUX) were then diagnosed by averaging over the last 5 years, values being sampled every 3 days. The diagnosed fields were then used to calculate the reference temperatures used in the alternative surface boundary conditions to be described next. The experiments using these alternative boundary conditions were initialized with the last field from the RS case.

\subsection{The Schopf Model (SM)}

This simple atmospheric model is taken from Schopf [1983], and it has been used by Zhang et al. [1993] and Greatbatch et al. [1995] at coarse horizontal resolutions to examine ocean-climate interaction. The governing equations of the model are

$$
\begin{gathered}
0=-K\left(T_{A}-T_{1}\right)-K_{r}{ }^{\prime} T_{A}-K_{r}{ }^{\prime} \delta T+Q_{a} \\
C_{o} \frac{\partial T_{1}}{\partial t}=K\left(T_{A}-T_{1}\right)+Q_{o}
\end{gathered}
$$

Equation (8) represents the heat balance for the atmosphere, based on the assumption that the heat capacity of the atmosphere is negligible compared with that of ocean. $T_{1}$ is the sea surface temperature, taken to be the same as the top model level temperature, and $T_{A}$ is the equivalent atmospheric temperature. $C_{o}$ and $K$ are the same as those in the RS condition; $K_{r}^{\prime}$ is the atmospheric radiative feedback constant, and $\delta T$ is the difference between the equivalent atmospheric temperature and the actual atmospheric temperature. $Q_{a}$ and $Q_{0}$ denote atmospheric and oceanic heat sources, respectively, not explicitly represented in the equations, such as advection, convective overturning, and solar radiation. The $\delta T$ in (8) is small compared to $T_{A}$ [Haney, $1971]$, and is usually neglected.

The above equations can be combined as [Schopf, 1983; Zhang et al., 1993],

$$
C_{o} \frac{\partial T_{1}}{\partial t}=K_{r}\left(T_{r}-T_{1}\right)+Q_{o}
$$

where

$$
T_{r}=\frac{Q_{a}}{K_{r}{ }^{\prime}}-\delta T
$$


(a)

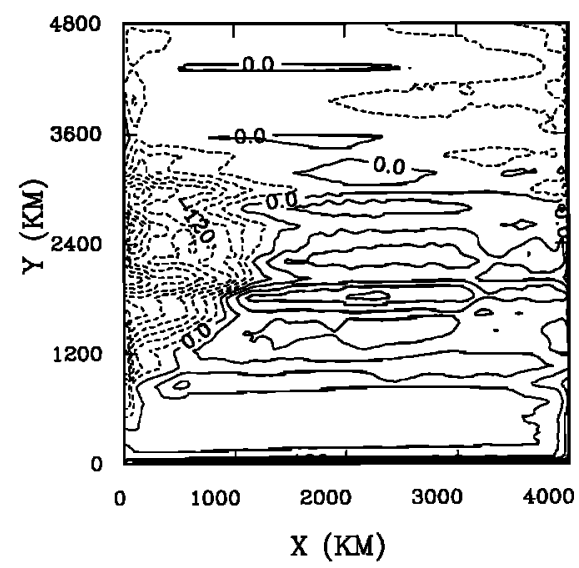

(b)

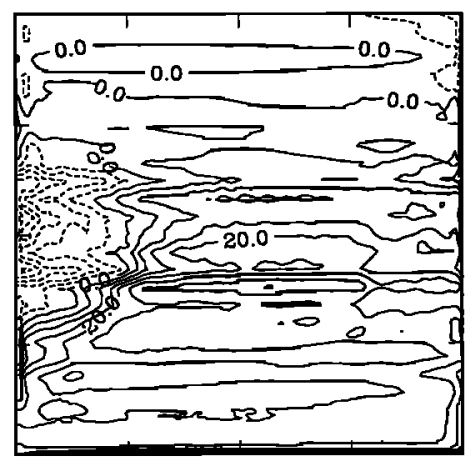

Figure 2. (a) The horizontal distribution of the 5-year mean surface heat flux (FLUX) from the restoring condition (RS) spin-up (contour interval $=30 \mathrm{~W} \mathrm{~m}^{-2}$ ) and (b) the corresponding reference temperature $T_{r}$ for the $S \operatorname{chopf}[1983]$ model $(\mathrm{SM})\left(\right.$ contour interval $\left.=5^{\circ} \mathrm{C}\right)$

$$
K_{r}=\frac{K K_{r}{ }^{\prime}}{K+K_{r}{ }^{\prime}}
$$

$T_{r}+\delta T$ is the radiative equilibrium surface temperature with constant atmospheric heating and without ocean dynamics [Schopf, 1983].

The RS condition is essentially the same as SM, but with $T_{A}$ fixed. By using the SM condition, $T_{r}$ is fixed, but $T_{A}$ is not fixed anymore and can be calculated as follows,

$$
T_{A}=\frac{K T_{o}+K_{r}{ }^{\prime} T_{r}}{K+K_{r}{ }^{\prime}}
$$

Since $K_{r}{ }^{\prime}$ is much smaller than $K$, the above equation can be reduced to $T_{A}=T_{o}+O\left(K_{r}{ }^{\prime} / K\right)$, meaning that $T_{A}$ (and the corresponding atmospheric temperature $T_{A}+\delta T$ ) is never far removed from the underlying SST. SM is, however, a purely local model, with no dependence on the horizontal scale of the SST anomaly, which may be the chief weakness from an eddy resolving point of view. We shall address this issue when we discuss the RW boundary condition.

To compare with the results obtained using a restoring condition, we diagnosed the 5-year mean heat flux (FLUX) and SST $\left(\overline{T_{1}}\right)$ from the RS condition and calculated the reference temperature $T_{r}$ for the SM model (Figure 2), using (from (10))

$$
T_{r}=\frac{F L U X}{K_{r}}+\overline{T_{1}}
$$

The surface forcing in the SM model can be written as

$$
A_{H V} T_{z}=\frac{\Delta z_{1}\left(T_{r}-T_{1}\right)}{\tau_{R 2}}
$$

where $\tau_{R 2}=C_{o} / K_{r}, T_{1}$ is the sea surface temperature at the top level and (14) is applied at the surface, $z=0$. Note that the restoring term in (14) has the same form as the conventional restoring boundary condition. Since $T_{r}$ is calculated using the diagnosed flux from the RS condition, the mean surface temperature for the SM model is almost identical to that for the RS condition. The restoring timescale $\tau_{R 2}$ here is 360 days for $\Delta z_{1}=50$ $\mathrm{m}$ and is much longer than the several tens of days typical of the conventional restoring condition.

According to (12), $K_{r}$ is very close to $K_{r}{ }^{\prime}$ because $K$ is much larger than $K_{r}{ }^{\prime}$ [Schopf, 1983]. If $K_{r}=2.4$ $\mathrm{W} \mathrm{m}{ }^{-2} \mathrm{~K}^{-1}$ [Dickinson, 1981; Schopf, 1983], then the restoring timescale will be about 1000 days for $\Delta z_{1}=$ $50 \mathrm{~m}$. We used 360 days, based on two considerations. First, the 1000-day timescale applies to a global scale SST anomaly, whereas our model domain is less than $5000 \mathrm{~km}$ in north/south and east/west extent [Bretherton, 1982]. Second, using a longer restoring time $\tau_{R 2}$ would mean having to run the high-resolution eddyresolving model for much longer, in order to achieve a statistical equilibrium.

There are some physical considerations in support of using the SM rather than the RS condition. The RS condition represents a strong negative feedback between SST and surface air temperature. In a recent satellite observational study, Liu et al. [1994] show that the coupling between the ocean and atmosphere is usually weak (long restoring timescale). There is also evidence that a positive feedback of heat flux can occur in reality [Favorite and McClain, 1973; Liu et al., 1994]. This has been shown theoretically by Pedlosky [1975] and also in a coupled atmosphere-ocean general circulation model (GCM) (W. Xu et al., manuscript in preparation, 1995).

\subsection{The Rahmstorf and Willebrand Models (RW0 and RW1)}

Bretherton [1982] noted the mechanisms for damping sea surface temperature anomalies depend on the horizontal scale of these anomalies. For anomalies of scale of a few tens of kilometers or less, atmospheric heat transport plays a major role; the heat removed by the wind is returned to the ocean elsewhere on the surface of the Earth. This mechanism damps SST anomalies 
on timescales of tens of days, as through the Haneytype [Haney, 1971] restoring condition. However, the damping for larger-scale anomalies is likely to be radiative relaxation to space, as there is nowhere for heat to be advected and reabsorbed by the ocean. The loss to space occurs on the much longer timescale of hundreds of days.

RW proposed a (linearized) energy balance model as the surface thermal boundary condition for ocean climate models. At the surface, $z=0$, this takes the form

$$
\begin{aligned}
A_{H V} T_{z} & =\frac{1}{\rho_{o} C}\left[\gamma\left(T^{*}-T_{1}\right)-\mu \nabla^{2}\left(T^{*}-T_{1}\right)\right] \\
& =\frac{\Delta z_{1}\left(T^{*}-T_{1}\right)}{\tau_{R 3}}-\frac{\mu}{\rho_{o} C} \nabla^{2}\left(T^{*}-T_{1}\right)
\end{aligned}
$$

where $T^{*}$ is the atmospheric equilibrium temperature if the ocean transports no heat [Marotzke, 1994]. For simplicity, $T^{*}$ is assumed to be zonally uniform. The coupling constant $\gamma$ in this case is much weaker than the air-sea exchange coupling, namely, 2 or $3 \mathrm{~W} \mathrm{~m}^{-2} \mathrm{~K}^{-1}$. The corresponding restoring time $\tau_{R 3}$ is between 700 and 1000 days for $\Delta z_{1}=50 \mathrm{~m}$. To compare with other experiments, we used 360 days in this study instead. The second term in (15) represents the divergence of atmospheric heat transport and is parameterized in terms of a diffusion law. It allows the model atmosphere to respond to changes in the ocean circulation by dispersing some of the heat it receives from the ocean (RW). Theoretically, $T^{*}$ can be solved from an atmospheric GCM [Marotzke, 1994]. For our process study it can be solved from the RS spin-up case by assuming that the zonally averaged mean SST is the same as that obtained from the RS condition, given $\gamma$ and $\mu$, i.e.,

$$
\frac{F L \hat{U} X}{C_{o}}=\frac{\left(T^{*}-\hat{T}_{1}\right)}{\tau_{R 3}}-\mu^{*} \frac{\partial^{2}\left(T^{*}-\hat{T}_{1}\right)}{\partial y^{2}}
$$

where $\tau_{R 3}=C_{o} / \gamma, \mu^{*}=\mu / C_{o}$ and $\hat{T}_{1}$ and $F L \hat{U} X$ are the zonal averages of the time mean temperature in the surface level of the model and the surface heat flux, respectively, diagnosed from the RS experiment.

3.3.1. RW0: No Atmospheric Heat Diffusion. For this boundary condition we use (15) with $\mu=0$. Equation (15) then has the same form as (14), with $T^{*}$ equal to the zonal average of $T_{r}$ and $\tau_{R 2}=\tau_{R 3}$. As we mentioned before, the mean surface temperature in the SM model is constrained to be the same as in the RS case. Although the use of a longer restoring time with the SM model releases the surface temperature, as far as the eddy variability is concerned (as we shall see later), the mean surface temperature is still constrained by the $T_{A}$ used in the restoring spin-up experiment (see Figure 2). Using the zonal average of $T_{r}$ has the effect of releasing the constraint placed on the time-averaged surface temperature, as well as on the eddy variability. Note that RW0 can be considered as a special case of both the SM and the RW1 models.
3.3.2. RW1: With Atmospheric Heat Diffusion. If $\mu$ is not zero, then the atmospheric heat transport is represented by a simple diffusion term. As already pointed out by RW and Marotzke [1994], this term gives increasing dissipation at small scale due to the linearization used in the RW derivation. For our eddy-resolving study we would like to not overdamp the smaller-scale features at the surface. We thus choose $\mu=10^{11} \mathrm{~W} \mathrm{~K}^{-1}$, which corresponds to a coupling sensitivity of about $110 \mathrm{~W} \mathrm{~m}^{-2} \mathrm{~K}^{-1}$ at the grid scale of 30 $\mathrm{km}$ [see Marotzke, 1994]. This magnitude of $\mu$ is equal to a diffusion of $5 \times 10^{6} \mathrm{~cm}^{2} \mathrm{~s}^{-1}$, which has a damping timescale of about 20 days at the grid scale (30 $\mathrm{km})$. Bretherton [1982] pointed out, based on results from atmospheric GCMs, that the air-sea coupling is dependent on spatial scale, being around $100 \mathrm{~W} \mathrm{~m}^{-2}$ ${ }^{\circ} \mathrm{C}^{-1}$ for SST anomalies a few tens of kilometers across but only $2 \mathrm{~W} \mathrm{~m}^{-2}{ }^{\circ} \mathrm{C}^{-1}$ for a change in SST averaged over the whole globe. These effects are included in (15). The diffusion term dominates at very small scale. For large spatial scale the diffusion term is negligible and the restoring term dominates.

The reference temperatures $T^{*}$ for both the RW0 and RW1 cases are shown in Figure 3. The wavy structure in Figure 3a is a consequence of the structure in the equivalent atmospheric temperature field shown in Figure 1a. The wavy structure is greatly reduced when the atmospheric heat transport is explicitly parameterized as a diffusion (Figure $3 \mathrm{~b}$ ).

A number of experiments have been performed, in order to determine the effects of different surface tem-
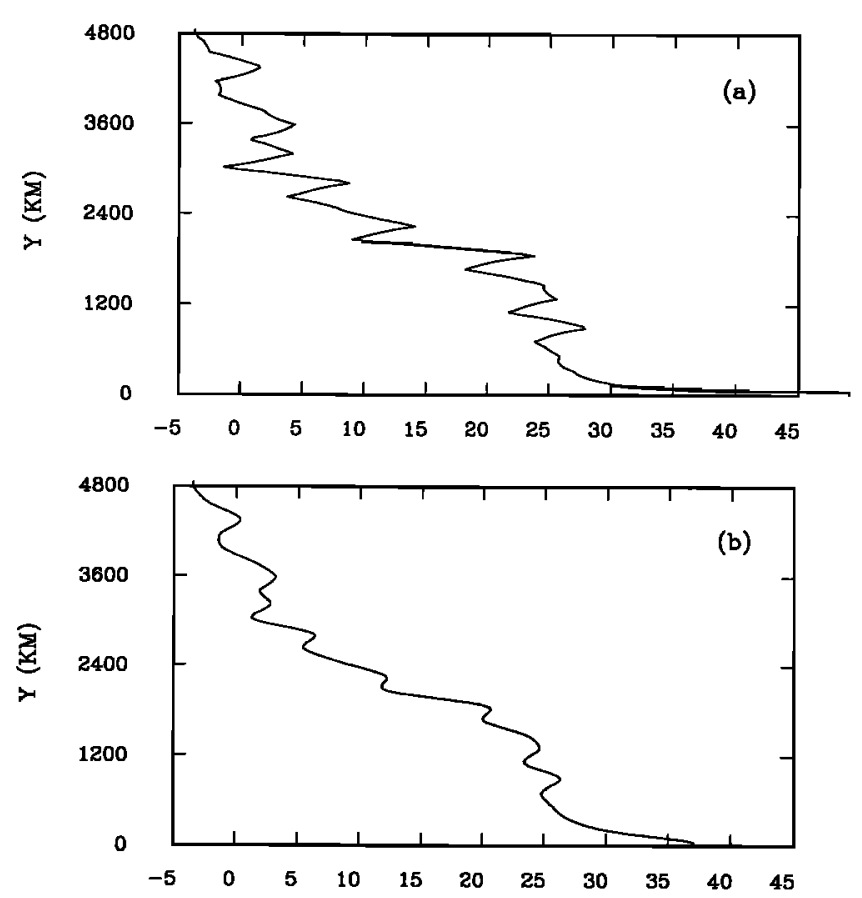

Figure 3. The reference temperature $T^{*}$ (degrees Celsius) for (a) the Rahmstorf and Willebrand [1995] (RWO) model with no atmospheric heat diffusion and (b) the RW model with atmospheric heat diffusion (RW1). 
perature boundary conditions. A preliminary experiment using the surface restoring boundary condition has the restoring timescale doubled from 30 to 60 days. An overall increase in the temperature variance $\overline{T^{\prime 2}}$ is obtained, but its vertical distribution is largely unchanged, with the maximum amplitude at subsurface levels within the thermocline. This is consistent with the results of Böning and Budich [1992], who used a restoring timescale of 50 days and obtained a similar vertical distribution.

In the rest of this paper we compare results obtained with the four different surface thermal boundary conditions at a horizontal resolution of $30 \mathrm{~km}$. Both horizontal and vertical distributions of eddy quantities are examined.

\section{Horizontal Distributions}

Figure 4 shows the simulated mean surface temperature distribution. Though the surface temperature in the SM case is not as constrained as in the case of RS condition, the mean temperature in the SM case is very similar to that in the RS case. This is expected because in the SM model the surface heat flux is derived from the restoring experiment (Figure 2). In contrast, the RW0 and RW1 models produce important differences in the mean state, which show realistic east-west asymmetrical structure, structure that is generated by the model dynamics. A heat balance study for these different boundary conditions is in preparation.

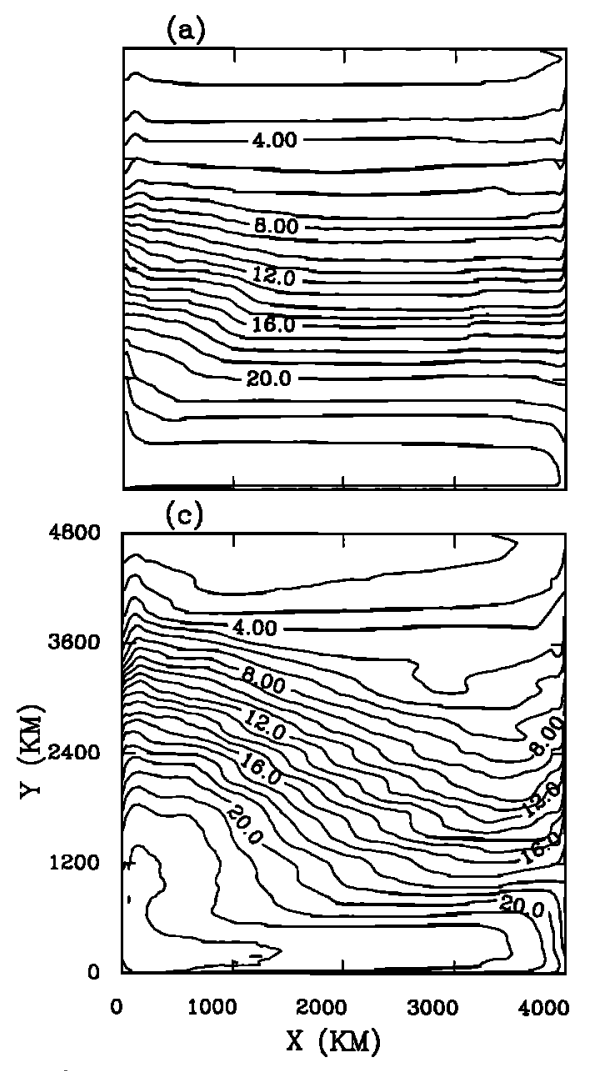

Examination of the instantaneous surface pressure for different surface boundary conditions (not shown) reveals that the coherent, separated jet near the midlatitude western boundary is more energetic and has greater penetration into the interior under the RW 0 and RW1 surface boundary conditions than in the RS and SM cases. This demonstrates that separation of the western boundary current in eddy-resolving models is sensitive to the choice of surface boundary condition [e.g., Ezer and Mellor, 1992].

Figure 5 shows the temperature variance $\overline{T^{\prime 2}}$ at the surface $(25 \mathrm{~m})$. The SM model yields a larger variance at the surface, with enhanced eastward extension of the high-variance region from the western boundary current into the open ocean. There is even stronger eastward extension in the RW0 and RW1 models associated with the stronger separated jets. Both RW0 and RW1 have two maximum centers, as shown by the bold contours; one is near the midlatitudes and the other in the eastern subtropical gyre. Especially, the temperature variance in the southeastern part of the domain is much stronger in the RW0 and RW1 cases than that in the RS and SM cases. This is associated with the different mean states in these cases. Spall [1990] found that the Community Modeling Effort (CME) [Bryan and Holland, 1989] model underestimated the eddy variability in the Canary Basin by about a factor of 5 . Our results show that the form of the surface boundary condition can increase eddy variability in those regions. Temperature variance is an important diagnostic, as the eddy

(b)

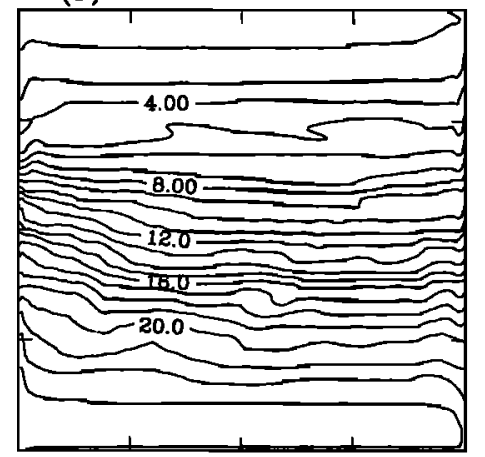

(d)

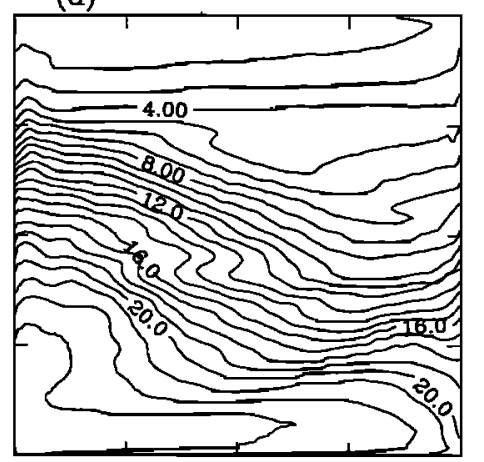

Figure 4. The 5-year mean sea surface temperature (degrees Celsius) for (a) RS, (b) SM, (c) RW0, and (d) RW1. 
(a)
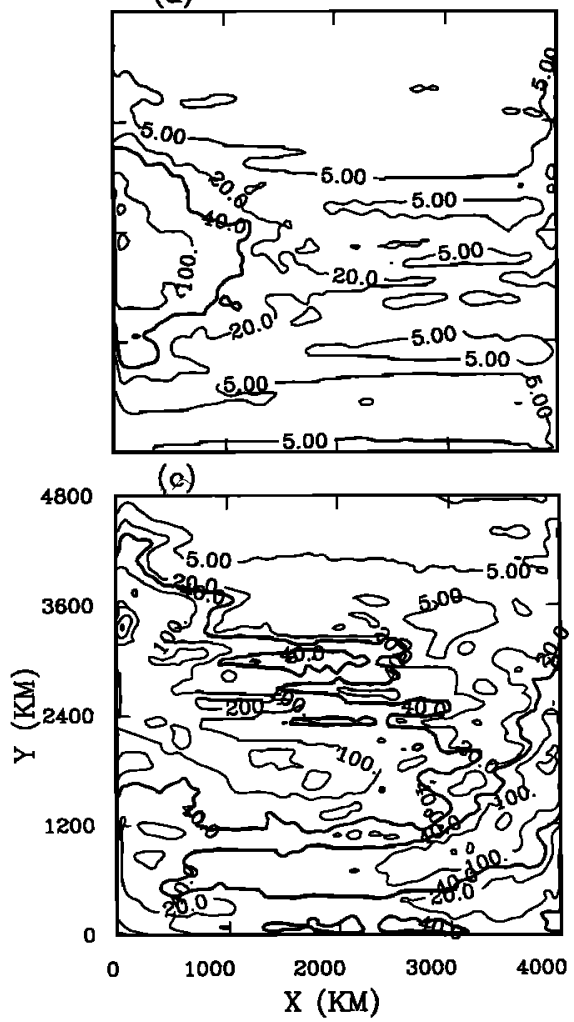

(b)

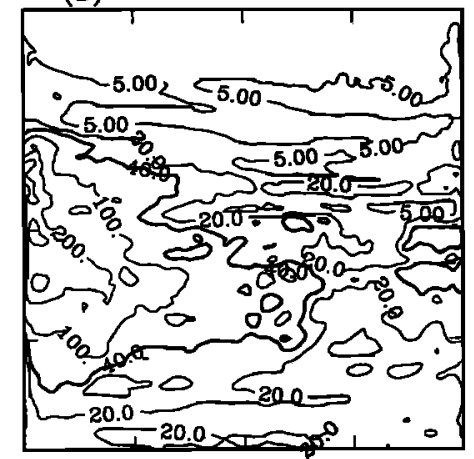

(d)

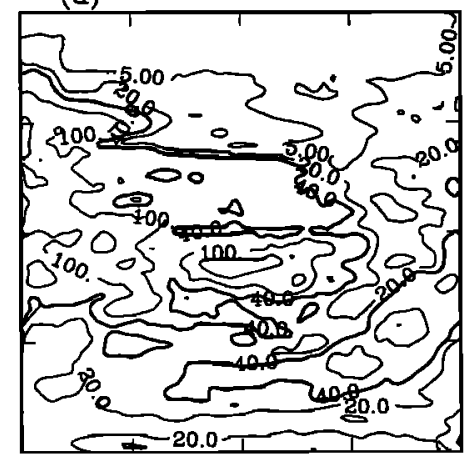

Figure 5. The 5-year mean temperature variance $\overline{T^{\prime 2}}\left(10^{-2} \times{ }^{\circ} \mathrm{C}^{2}\right)$ at depth $25 \mathrm{~m}$ for (a) RS, (b) SM, (c) RW0, and (d) RW1. Note that the magnitudes of the temperature variance here were multiplied by a factor of 100 .

(a)

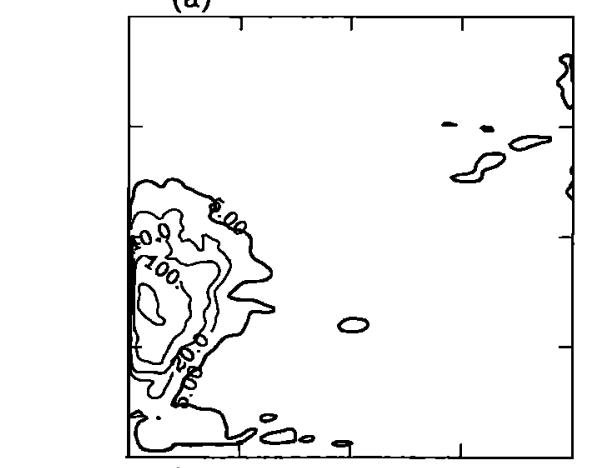

(c)

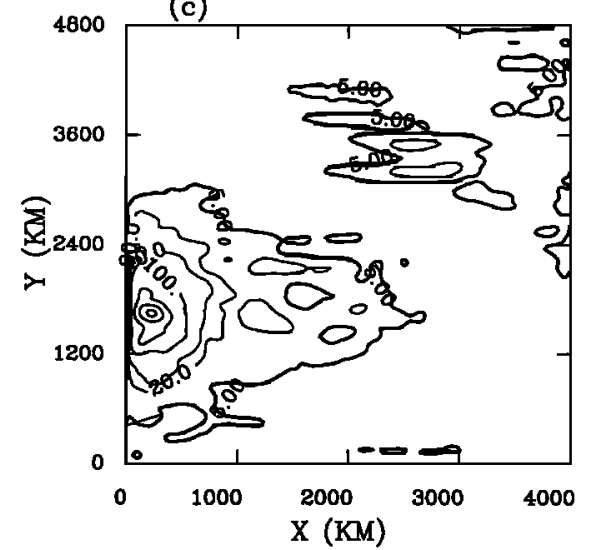

(b)

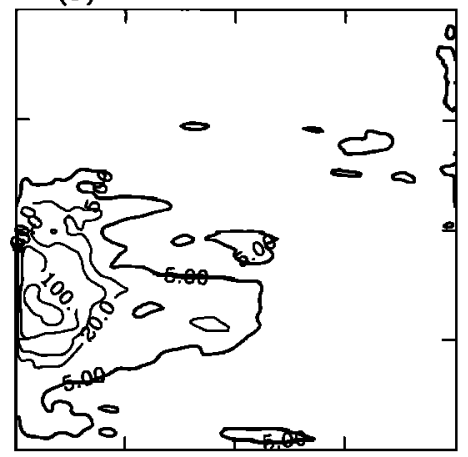

(d)

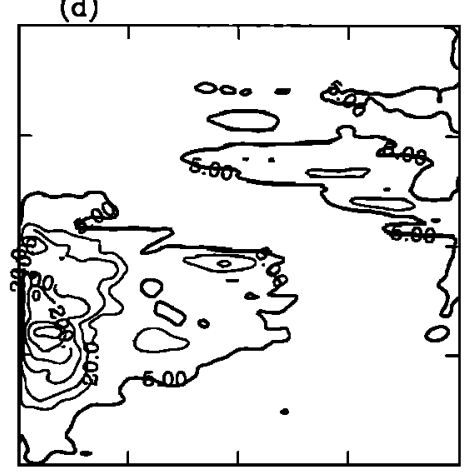

Figure 6. Same as Figure 5, but for depth $400 \mathrm{~m}$. 

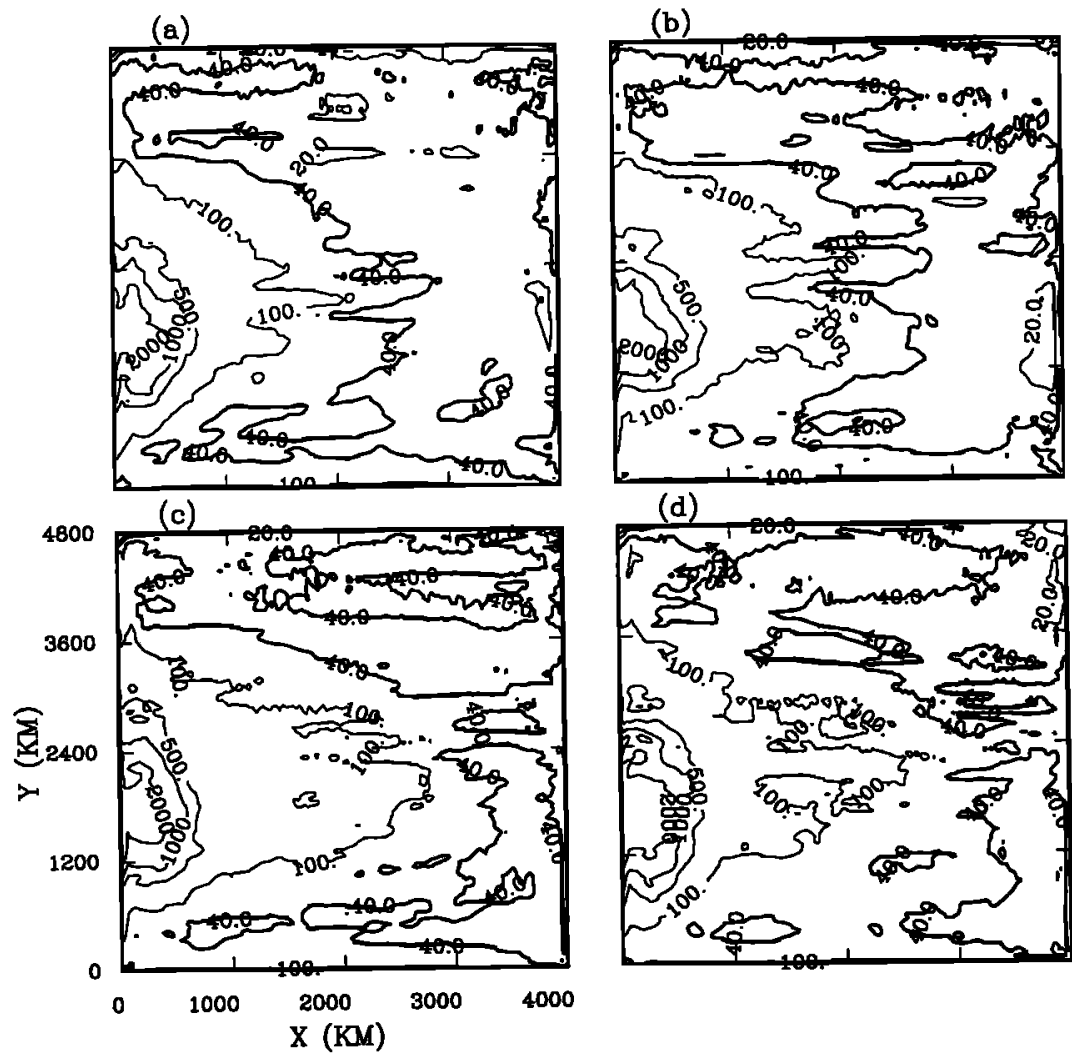

(d)

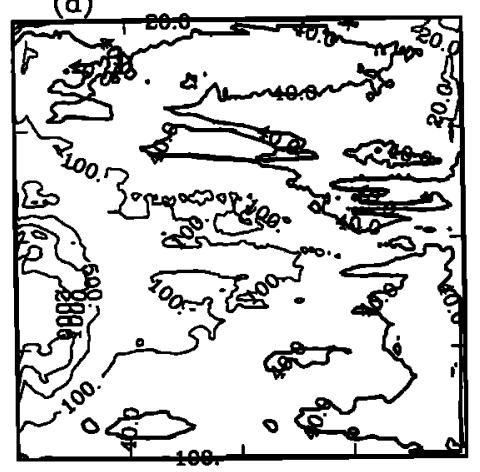

Figure 7. The 5-year mean eddy kinetic energy $\overline{K^{\prime}}$ (square centimeters per second squared) at depth $25 \mathrm{~m}$ for (a) RS, (b) SM, (c) RW0, and (d) RW1.

available potential energy is equal to the temperature variance normalized by the mean stratification.

Figure 6 shows the temperature variance at $400 \mathrm{~m}$, within the thermocline. The larger eastward extension is evident for the SM, RW0, and RW1 cases compared with the RS case. Comparing the simulated variance distributions at this level with observations [Emery, 1983; Dantzler, 1977], we see that the overall pattern is consistent with the observations near the western boundary current region, though the model may not resolve all the physics to reproduce the observation. As we know, all the eddy-resolving ocean models underestimate the variability downstream of the western boundary current in the northeastern part of the domain. However, the SM, RW0, and RW1 models do have stronger variability in this region. A higher horizontal resolution with lower diffusivities is probably needed to get better quantitative agreement.

Figure 7 shows the eddy kinetic energy $\overline{K^{\prime}}$ at the surface. The distributions obtained with the RS are generally similar to the simulations of $\operatorname{Cox}$ [1985], and Böning and Budich [1992]. The current observational estimates of $\overline{K^{\prime}}$ are based on ship drift measurements [Wyrtki et al., 1976], drifting buoys [Richardson, 1983; Arhan et al., 1989; Colin de Verdiere et al., 1989], and Geostat altimetry [Le Traon et al., 1990; Stammer and Böning, 1992]. These estimates generally agree on the overall $\overline{K^{\prime}}$ pattern but not on the magnitudes due to the different smoothing used in the studies. Treguier [1992] and Stammer and Böning [1992] found the CME model underestimates $\overline{K^{\prime}}$ at midlatitude near the axis of maximum $\overline{K^{\prime}}$ and in the eastern North Atlantic. Our results show that a larger $\overline{K^{\prime}}$ in the northeastern part of the basin is simulated using the the SM, RW0, and RW1 models compared with the RS condition. This increase is due to resolved baroclinic instability, which, in turn, is due to the less constraining surface condition of the SM, RW0, and RW1 models. In the western boundary current region the magnitudes for the four cases are about the same. The increase in $\overline{K^{\prime}}$ is not as pronounced as the increase in temperature variance examined in Figure 5, as the horizontal resolution is still not high enough; the small-scale eddies are thus still effectively dissipated by the highly scale-selective frictions. However, we also note that there is an increased conversion of $\overline{K^{\prime}}$ to $\bar{K}$ (mean kinetic energy) for the SM model; this aspect was examined in detail by $X u$ [1994].

Figure 8 shows the distribution of $\bar{K}$. The RW0 and RW1 models give larger values of $\bar{K}$ in the midlatitude open ocean, as well as an increased eastward extension of the zonal bands, than both the RS condition and SM model. The simulated mean flow has a maximum $\bar{K}$ of about $100 \mathrm{~cm}^{2} \mathrm{~s}^{-2}$ near the north equatorial current, $4000 \mathrm{~cm}^{2} \mathrm{~s}^{-2}$ near the western boundary current, and $20 \mathrm{~cm}^{2} \mathrm{~s}^{-2}$ in the open ocean. A minimum is found in the center of the subtropical gyre. This overall pattern 
(a)

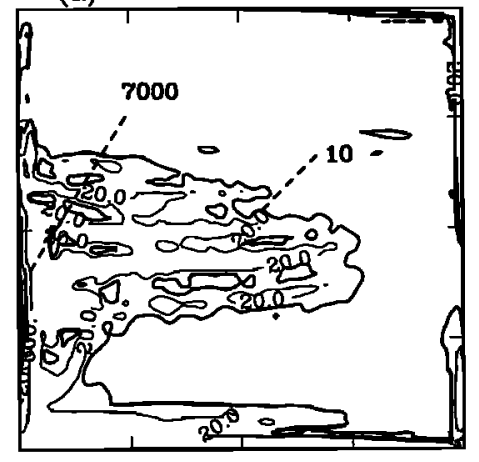

(c)

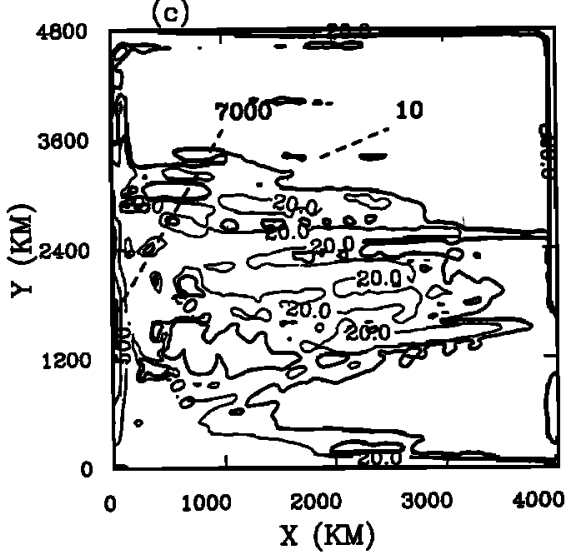

(b)

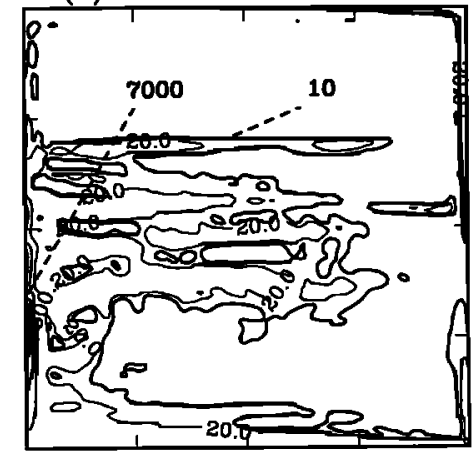

(d)

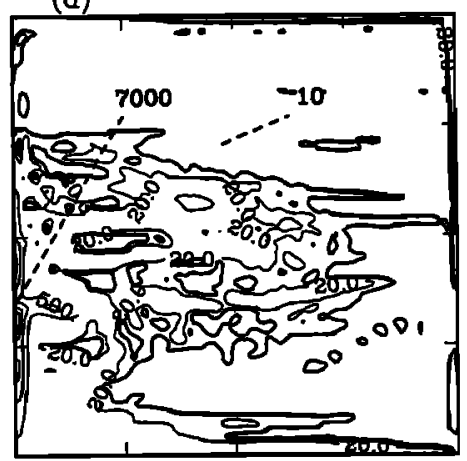

Figure 8. The 5-year mean kinetic energy $\bar{K}$ (square centimeters per second squared) at depth $25 \mathrm{~m}$ for (a) RS, (b) SM, (c) RW0, and (d) RW1.

agrees with the observational estimates of Wyrtki et al. [1976]. The $\bar{K}$ is, however, underestimated in the separation region; this is not surprising, as topography is not included in our model, so that the free jet in the RW0 and RW1 cases is not anchored and separates at different places along the boundary at different times. Primitive equation models are known to have difficulties in simulating the separation of western boundary current [Bryan and Holland, 1989; Treguier, 1992; Böning and Budich, 1992]. Our main point here is to show that the use of the RW0 and RW1 models provides a mechanism to increase both $\bar{K}$ and $K^{\prime}$ levels and an enhanced eastward extension of mesoscale variability and mean flow into the eastern North Atlantic. Böning and Budich [1992] found that the eastward extension of $\overline{K^{\prime}}$ and $\bar{K}$ respond differently to an increase in horizontal resolution; the eastward extension of $\overline{K^{\prime}}$ was increased substantially for the finer resolution, while the eastward extension of $\bar{K}$ did not change correspondingly. This is in contrast to the wind-driven quasi-geostrophic (QG) model result of Holland and Schmitz [1985] and Barnier et al. [1991]. One of the possible reasons is the strong damping effect of diffusion in primitive equation (PE) models [Holland and Batteen, 1986]. Indeed, our results suggest that the eastward extension of both $\bar{K}$ and $\overline{K^{\prime}}$ can be increased by relaxing the surface temperature condition through the RW0 and RW1 models.

\section{Vertical Distributions}

Figure 9 shows the vertical profile of horizontally domain-averaged mean temperature variance $\overline{T^{\prime 2}}$ and eddy kinetic energy $\overline{K^{\prime}}$. There is significant difference of the domain-averaged $\overline{T^{\prime 2}}$ among the different surface boundary conditions. A larger $\overline{T^{\prime 2}}$ is found in the top levels for the SM model compared with the RS condition. For the RW0 and RW1 models, much larger $\overline{T^{\prime 2}}$ is found in both the deep and upper ocean. Figure $8 \mathrm{~b}$ shows that stronger $\overline{K^{\prime}}$ is obtained with the increase of $\overline{T^{\prime 2}}$ with the RW0 and RW1 models. However, the change of $\overline{K^{\prime}}$ for the SM compared with the RS case is insignificant for the basin average.

Figure 11 shows the distribution of $\overline{T^{2}}$ with depth for the different sub-regions which are shown in Figure 10. The vertical profile of temperature variance for the RS condition is consistent with that of Böning and Budich [1992], with maxima at the subsurface level. Figures 11a and 11c show the vertical profile of temperature variance in the western part of the subtropical gyre and midlatitude ocean. The SM model has much larger values at the surface than the RS condition, with little change in the thermocline region. In contrast to the SM model, both the RW0 and RW1 models have smaller variability than the SM model at the surface 

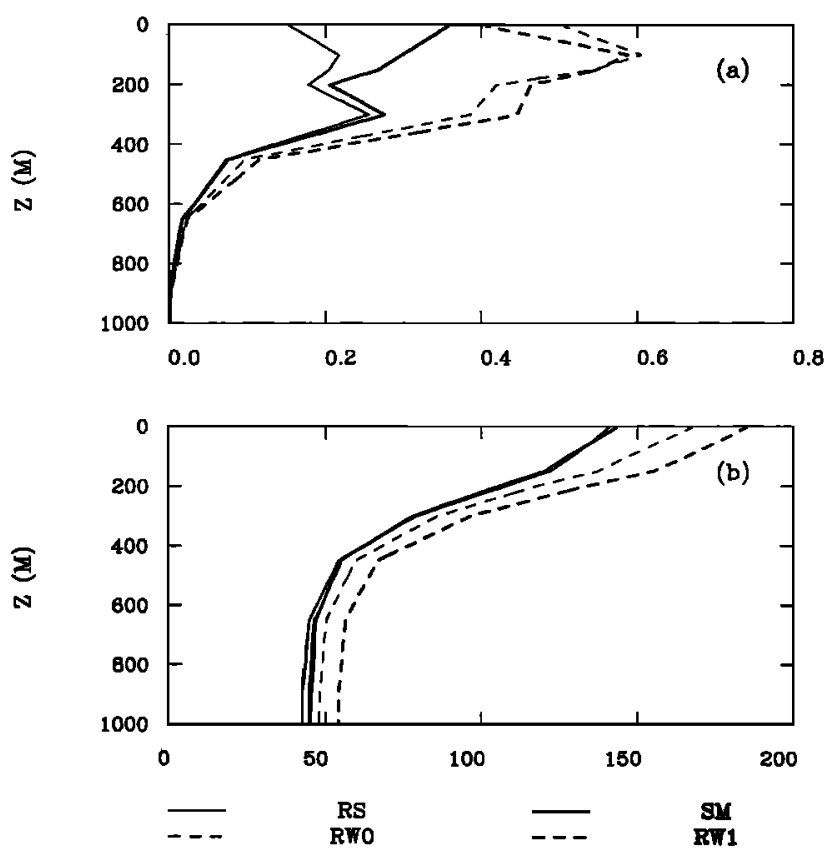

Figure 9. The vertical distribution of the (a) domainaveraged temperature variance $\overline{T^{\prime 2}}$ (degrees Celsius squared) and (b) domain-averaged mean eddy kinetic energy $\overline{K^{\prime}}$ (square centimeters per second squared) for the RS condition, the SM model, the RW0 model, and the RW1 model.

due to the northward shift of the isotherms in this region (see Figure 4) but have larger variability than both the RS condition and SM model in the thermocline region. In most of the other regions the RW0 and RW1 models have much larger variance in both surface and thermocline regions, especially in the eastern part of the ocean (Figures 11b, 11d and 11f). The difference between the RS condition and SM, RW0, and RW1 models is that the former has a strong negative feedback, and SST anomalies are effectively removed by the boundary conditions.

Three different vertical distributions of $\overline{T^{2}}$ were observed in the North Atlantic, depending on the location

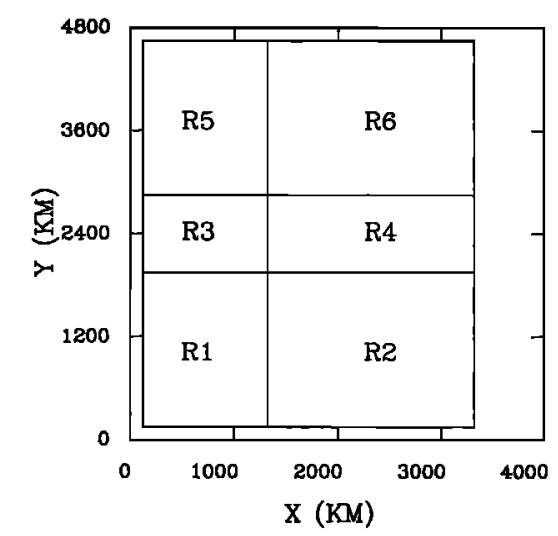

Figure 10. The locations of subregions R1, R2, R3, $\mathrm{R} 4, \mathrm{R} 5$, and $\mathrm{R} 6$ used in the regional study.
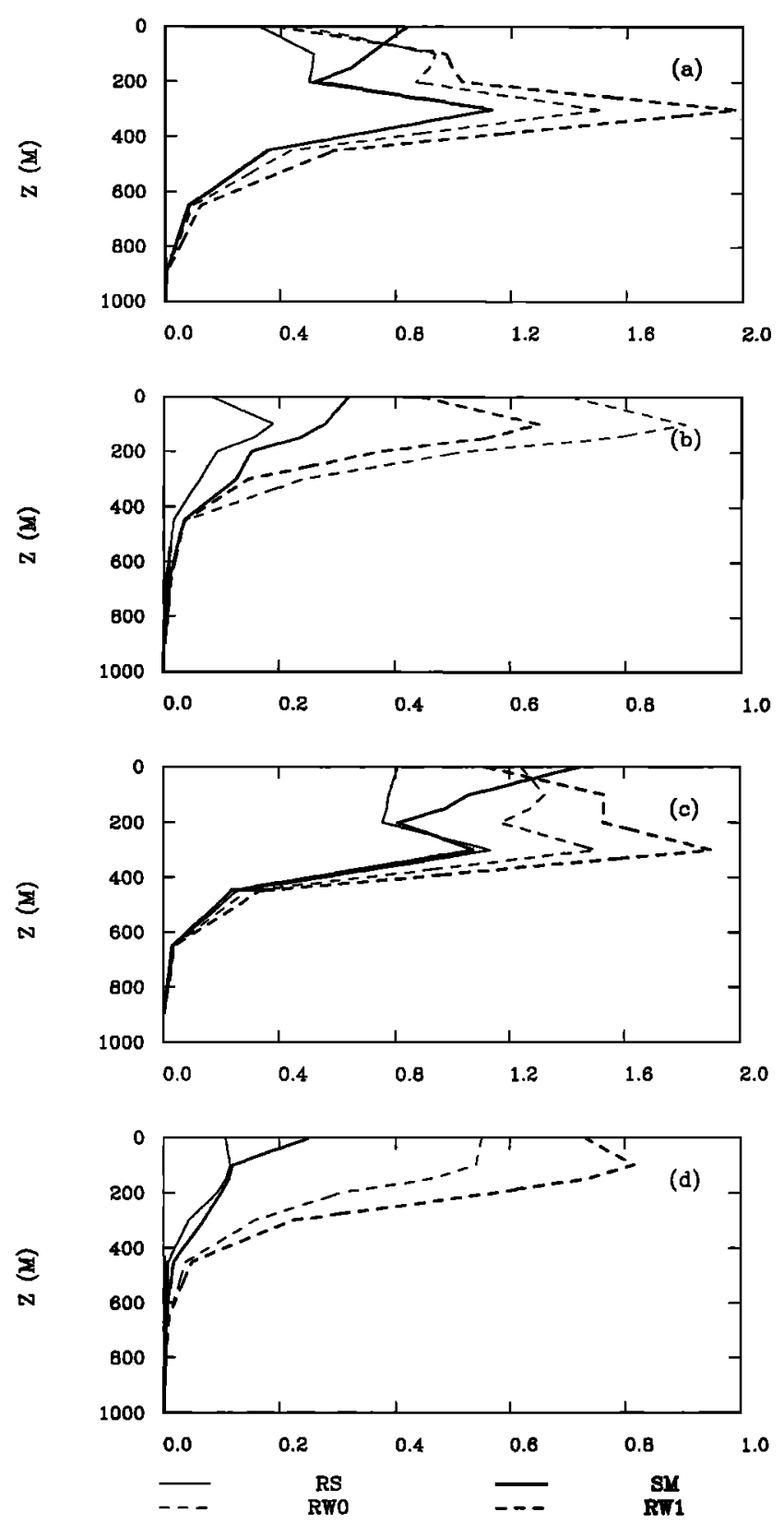

Figure 11. The vertical distribution of the mean temperature variance (degrees Celsius squared) in regions (a) R1, (b) R2, (c) R3, (d) R4, (e) R5, and (f) R6 for the RS condition, the SM model, the RW0 model, and the RW1 model.

[Fu et al., 1982; Wunsch, 1981, 1983]. The maxima of the temperature variance can be found at the surface, subsurface levels, or both. Emery et al. [1980] analyzed the multiship surveys in the area between 29 and $42^{\circ} \mathrm{N}$ in the North Pacific and North Atlantic Oceans and found many eddy signatures in the sea surface temperature field. In the subtropical region of the model all the boundary conditions lead to subsurface maxima of the temperature variance due to the presence of a strong thermocline. In the subpolar gyre, however, the SM, RW0, and RW1 models give a maximum temperature variance at the surface, while the restoring condition 

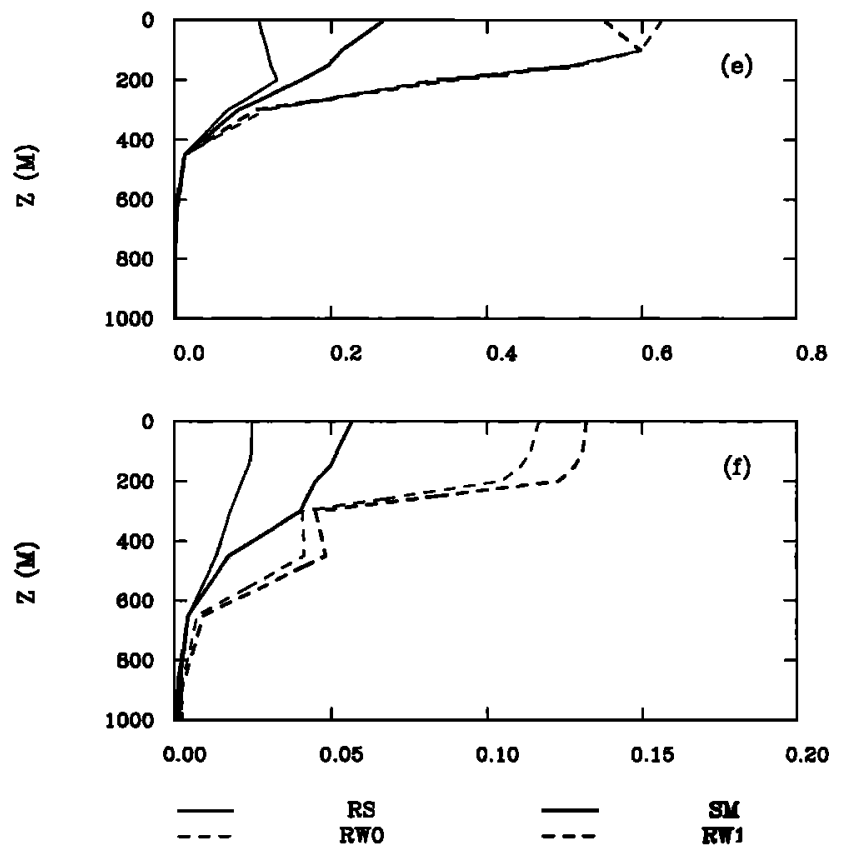

Figure 11. (continued)

still has the maximum at subsurface levels. The former results may be more consistent with the fact that the meridional temperature distribution shows no clear thermocline in the subpolar gyre of the model.

We next show the relationship between $\overline{K^{\prime}}$ and $\overline{w^{\prime} T^{\prime}}$; the latter is a measure of baroclinic instability (Figure 12). To isolate both barotropic and transport processes, which are very important near the western boundary current, from the baroclinic instability, we only examine the eastern part of the model domain, where the barotropic instability is negligible and transport processes are relatively small. We can see that the increase of eddy kinetic energy $\overline{K^{\prime}}$ is associated with the increase of baroclinic instability $\overline{w^{\prime} T^{\prime}}$ for different surface thermal boundary conditions (Figure 12), especially with the RW0 and RW1 models.

The increase is most pronounced near the surface, as for the temperature variance examined earlier. As measured by this diagnostic, the baroclinic instability of the subpolar gyre is enhanced in the upper ocean through the use of less constraining surface boundary conditions, but the maximum remains at a subsurface level. This is unlike the temperature variance, where the maximum in the subpolar gyre is located at the surface for the SM, RW0, and RW1 models. The use of the rigid top boundary condition, which sets the vertical velocity to zero at the surface (note the top level in Figures 11 and 12 is at $25 \mathrm{~m}$, i.e., the midpoint of the first model level), may underestimate the baroclinic instability (J. Dukowicz, personal communication, 1994).

As mentioned earlier, Treguier [1992] and Stammer and Böning [1992] compared the mesoscale variability in the CME model [(Bryan and Holland, 1989] with estimates from Geosat altimetry. They found that the model systematically underestimates the amplitude of the variability; they also note that the leading mechanism in generating eddy variability is baroclinic instability. Our results show that the use of the SM, RW0, and RW1 models, instead of the more conventional restoring condition, can produce stronger eddy variabilities when sufficient horizontal resolution is used. Böning [1989] showed that random topography can effectively remove the eddy kinetic energy in the deep ocean but
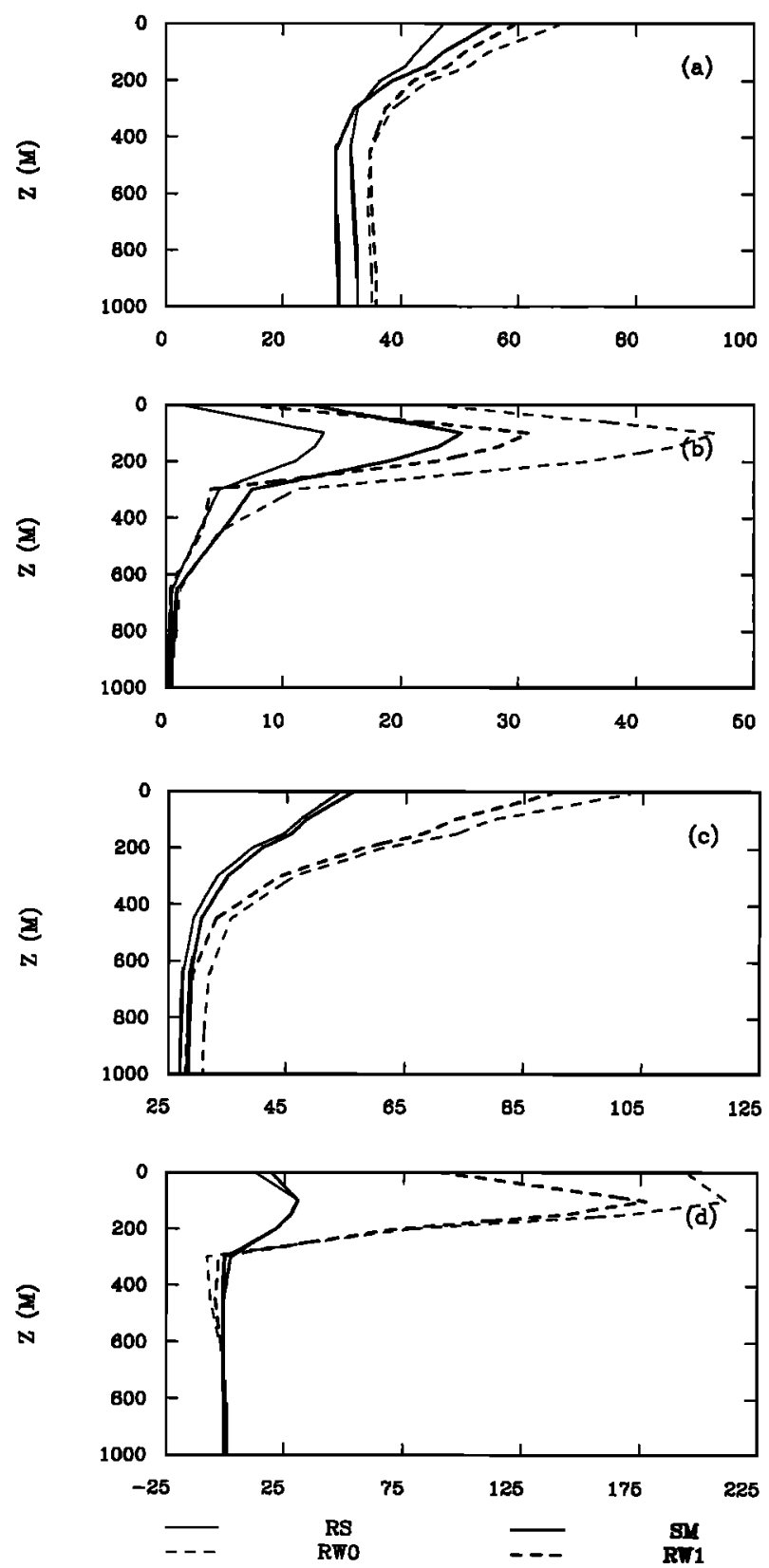

Figure 12. The vertical distribution of the mean eddy kinetic energy $\overline{K^{\prime}}$ (square centimeters per second squared) and the mean vertical heat transport $\overline{w^{\prime} T^{\prime}}$ $\left(10^{-6} \times{ }^{\circ} \mathrm{C} \mathrm{cm} \mathrm{s}^{-1}\right)$ in $\mathrm{R} 2$, (a) $\overline{K^{\prime}}$ and (b) $\overline{w^{\prime} T^{\prime}}$; in R4, (c) $\overline{K^{\prime}}$ and (d) $\overline{w^{\prime} T^{\prime}}$; in R6, (e) $\overline{K^{\prime}}$ and (f) $\overline{w^{\prime} T^{\prime}}$ for the RS condition, the SM model, the RW0 model, and the RW1 model. 

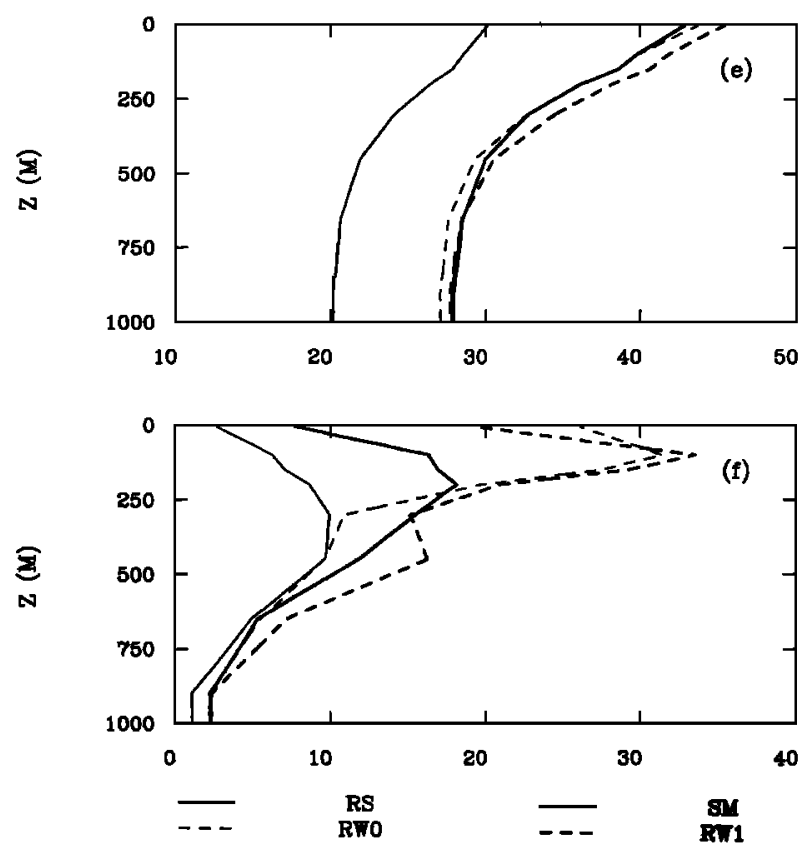

Figure 12. (continued)

leave it almost unchanged above the thermocline. Thus inclusion of topography increases the baroclinicity in the eddy flow. Our results here also show the increase of baroclinicity in the eddy flow but through the use of less constraining surface thermal boundary conditions.

\section{Northward Heat Transport}

Figure 13 shows the northward heat transport. The RS condition and SM model (Figures 13a and 13b) have very similar heat transport because the mean surface heat flux is the same in each case. The only possible difference between the RS and SM cases could be the distribution of the heat transport between the mean and the eddy parts. In both cases the heat transport by the time-varying flow is insignificant and the dominant heat transport is carried by the mean flow [Cox, 1985; Bryan, 1986, 1987, 1991; Bryan and Holland, 1989; Böning and Budich, 1992].

In contrast to the RS condition and SM model, the RW0 and RW1 models (Figures 13c and 13d) have a much larger northward heat transport, mainly due to the mean flow transport. Interestingly, the heat transport by eddies has a negative contribution compared with the RS case (Figure 14). This is a very interesting feature. The previous studies with the CME model [Bryan and Holland, 1989; Beckmann et al., 1994], which used a Haney-type [Haney, 1971] RS condition, have found that the heat transport is smaller than observed.

\section{Conclusions}

The effects of the four different surface thermal boundary conditions have been compared in an eddy-resolving model. The energy balance models (SM, RW0, and RW1), being less constraining than the restoring (RS) condition in terms of the surface temperature, allow more mesoscale variability near midlatitudes and eastern subtropical and subpolar gyres. The horizontal and/or vertical distribution of the temperature variance $\overline{T^{2}}$, eddy kinetic energy $\overline{K^{\prime}}$ and baroclinic instability $\overline{w^{\prime} T^{\prime}}$ are used in the comparison. Our results suggest that the use of less constraining surface boundary conditions is one way to increase mesoscale vari-
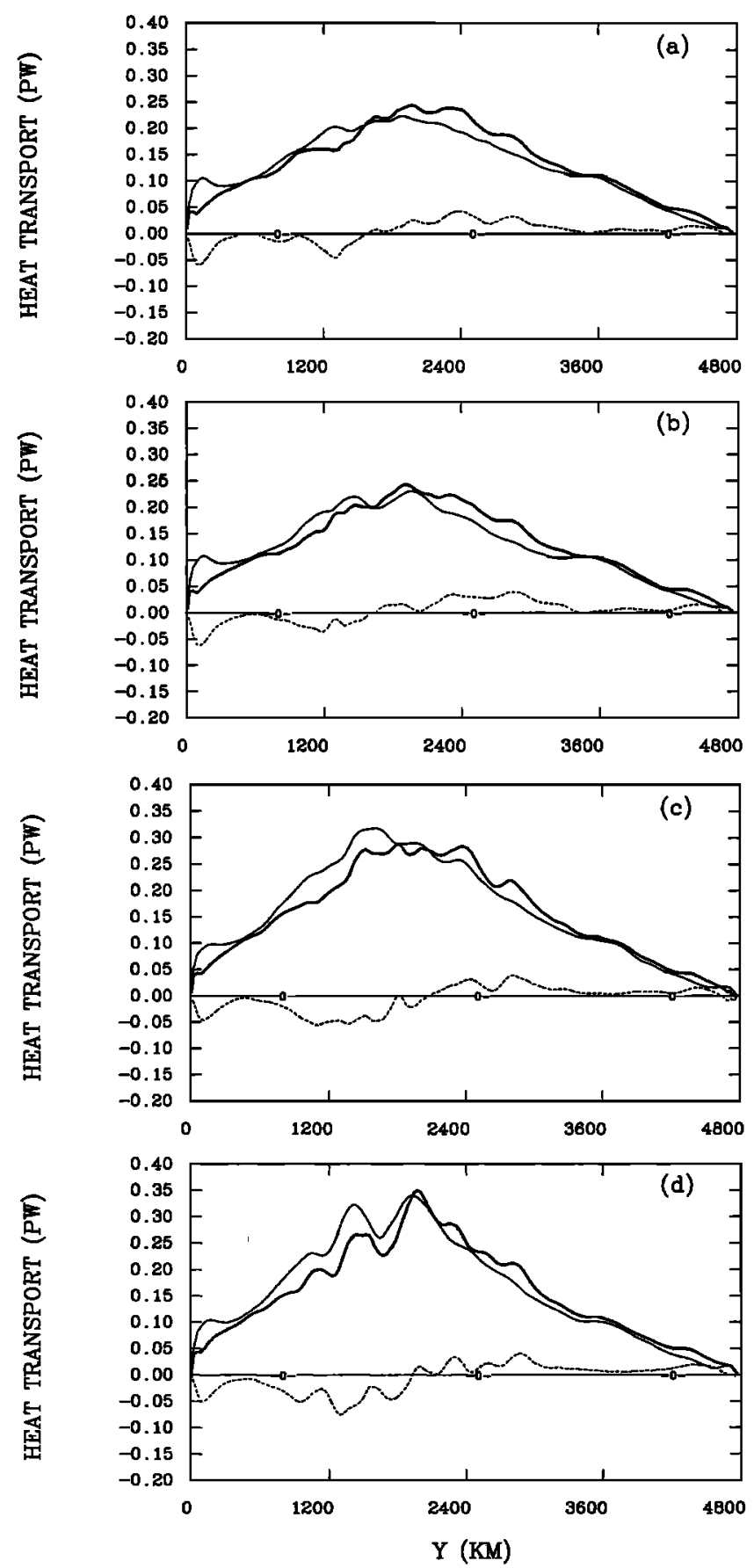

- MEAN FLOW COMPONENT

-..- EDDY COMPONENT TOTAL TRANSPORT

Figure 13. The northward heat transport (in petawatts) for (a) RS, (b) SM, (c) RW0, and (d) RW1. 

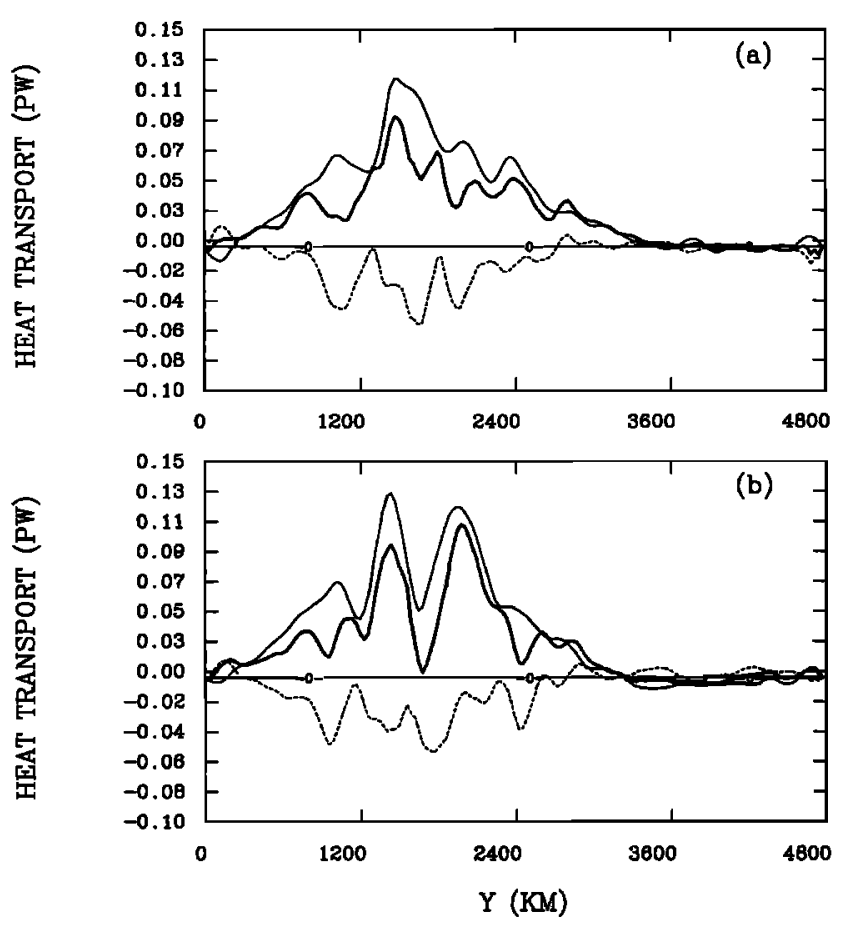

- MEAN FLOW COMPONENT

-... EDDY COMPONENT TOTAL TRANSPORT

Figure 14. The northward heat transport (in petawatts) for (a) difference between the RW0 and RS conditions and (b) difference between the RW1 and RS conditions.

ability through a strengthened midlatitude jet in eddyresolving models, though, of course, this need not necessarily be the only way. For example, the CME model, which used a Haney-type [Haney, 1971] RS condition, underestimated such variability in the eastward extension region of the Gulf Stream and in the subpolar gyre [Stammer and Böning, 1992; Treguier, 1992]. Another important result is that stronger mean kinetic energy $\bar{K}$ is found in the eastward extension region of the western boundary current in the SM, RW0, and RW1 cases. This is especially relevant as Böning and Budich [1992] found that the $\bar{K}$ eastward extension was not sensitive to the horizontal resolution when the RS condition was used. The sensitivity study with the SM model $[X u, 1994]$ indicates that the mean circulation becomes stronger when the horizontal resolution is increased.

The vertical distributions of temperature variance obtained with the SM, RW0, and RW1 models show maxima at the surface, subsurface level, or both, depending on geographical location. In contrast, the results we have obtained with the RS condition all show a temperature variance maximum below the surface. The vertical heat transport by the time-varying flow $\left(\overline{w^{\prime} T^{\prime}}\right.$, i.e., baroclinic instability), which converts eddy available potential energy $\overline{P^{\prime}}$ to eddy kinetic energy $\overline{K^{\prime}}$, is also increased in the SM, RW0, and RW1 models. The latter three boundary conditions permit the simulated sea surface temperature to depart more from the refer-

ence temperature and allow advection to play a larger role in the surface heat balance. Although the SM model is less constraining than the RS condition, it has stronger constraint than the RW0 and RW1 models due to the direct use of the surface heat flux diagnosed from the RS spin-up case. This can be easily seen from the vertical distribution of $\overline{7^{\prime \prime}}, \overline{K^{\prime}}$, and $\overline{w^{\prime} T^{\prime}}$. The primary reason for their difference is that both the SM model and RS condition have the same mean state, but RW0 and RW1 models release this mean state (Figure 4).

The northward heat transport is sensitive to the surface thermal boundary condition. Significantly, the heat transport in the RW0 and RW1 models is stronger than that in the RS condition and SM model and indicates that less restrictive surface boundary conditions are needed for ocean climate studies.

Our model results suggest a possible reason for the underestimate of eddy variability and northward heat transport in eddy-resolving models. We do not suggest that the form of the surface boundary conditions is the only reason, but we suggest this as an area for future investigation using models such as the CME.

\section{Notation}

$\tau_{R 1}, \tau_{R 2}, \tau_{R 3}, \tau_{R 4}$ $x, y, z$

$$
\boldsymbol{u}
$$

$f$ Coriolis parameter.

$\rho$ density of seawater.

$\rho_{0}$ reference density of seawater.

$T$ temperature.

$\alpha$ thermal expansion coefficient, $2.5 \times 10^{-4}{ }^{\circ} \mathrm{C}^{-1}$.

$D$ horizontal divergence.

$H$ depth of ocean.

$A_{M H}, A_{H H}$ horizontal viscosity and diffusivity.

$A_{M V}, A_{H V}$ vertical viscosity and diffusivity.

$\lambda$ eddy viscosity operating on the horizontal divergence.

$\tau_{x}, \tau_{y} \quad$ surface wind stresses in $x, y$ directions.

$T_{A}$ equivalent atmospheric temperature.

$T_{1}$ surface ocean temperature.

$\Delta z_{1} \quad$ the top layer model depth.

$C$ the specific heat of seawater.

$C_{o} \quad \rho_{0} C \Delta z_{1}$, the heat capacity of the ocean mixed layer.

$Q^{T} \quad$ restoring surface heat flux, $\Delta z_{1}\left(T_{A}-T_{1}\right) / \tau_{R}$.

$K$ the heat exchange coefficient across the air-sea interface. 
$K_{r}^{\prime} \quad$ the atmospheric radiative feedback constant.

$\gamma$ the coupling constant in the energy balance models.

$\mu$ constant of temperature diffusion in the energy balance model.

Acknowledgments. W. Xu thanks G. Flierl, W. Gough J. Marotzke, J. Marshall, S. Power, D. Stammer, D. Straub, A. Weaver, and S. Zhang for helpful discussion. Computing time on the NEC SX3 supercomputer for this work was provided by $M$. Béland of Recherche en prévision numérique, Atmospheric Environment Service (AES), Canada. Both C.A.L. and R.J.G. acknowledge support of grants from Natural Science and Engineering Research Council (NSERC), NSERC/WOCE, and AES. The use of the computing facilities of Centre de Recherche en Calcul Appliqué (CERCA) is also gratefully acknowledged. The comments of the two anonymous reviewers were very helpful in improving the manuscript. We are grateful to Joy Simmons (Memorial University) for preparing the camera ready manuscript.

\section{References}

Arakawa, A., and V.R. Lamb, Computational design of the basic dynamical processes of the UCLA general circulation model, in Methods Comput. Phys. 17, 173-265, 1977.

Arhan, M., A. Colin de Verdiere, and H. Mercier, Direct observations of the mean circulation at $48^{\circ} \mathrm{N}$ in the Atlantic Ocean, J. Phys. Oceanogr., 19, 1161-181, 1989.

Barnier, B., B.L. Hua, and C. Le Provost, On the catalytic role of high baroclinic modes in eddy-driven large scale circulations, J. Phys. Oceanogr., 21, 976-997, 1991.

Batteen, M.L., and Y.-J. Han, On the computational noise of finite difference schemes used in ocean models, Tellus, 33, 387-396, 1981.

Beckmann, A., C.W. Böning, C. Köberle, and J. Willebrand, Effects of increased horizontal resolution in a simulation of the North Atlantic Ocean, J. Phys. Oceanogr., 24, 326344, 1994.

Böning, C.W., Influence of a rough bottom topography on flow kinematics in an eddy-resolving circulation model, $J$. Phys. Oceanogr., 19, 77-97, 1989.

Böning, C.W., and R.G. Budich, Eddy dynamics in a primitive equation model: sensitivity to horizontal resolution and friction, J. Phys. Oceanogr., 22, 361-381, 1992.

Bretherton, F.P., Ocean climate modelling, Prog. Oceanogr., 11, 93-129, 1982.

Bryan, F., and W.R. Holland, A high-resolution simulation of the wind- and thermohaline-driven circulation in the North Atlantic Ocean, in Parameterisation of Small-Scale Processes, Proceedings of Aha Huliko'a Winter Workshop 1989, edited by P. Muller and D. Henderson, pp. 99-115, Hawaii Inst. of Geophys., Honolulu, 1989.

Bryan, K., Poleward buoyancy transport in the ocean and mesoscale eddies, J. Phys. Oceanogr., 16, 927-933, 1986.

Bryan, K., Potential vorticity in models of the ocean circulation, Q. J. R. Meteorol. Soc., 13, 713-734, 1987.

Bryan, K., The design of numerical models of the ocean circulation, in Oceanic Circulation Models: Combining Data and Dynamics, edited by D.L.T. Anderson and J. Willebrand, pp. 465-500, Kluwer Academic, Norwell, Mass., 1989.

Bryan, K., Poleward heat transport in the ocean: A review of a hierarchy of models of increasing resolution, Tellus, Ser. A, 43, 104-115, 1991.

Colin de Verdiere, A., H. Mercier, and M. Arhan, Mesoscale variability transition from the western to the eastern Atlantic along $48^{\circ} \mathrm{N}, J$. Phys. Oceanogr., 19, 1149-1170, 1989.

Cox, M.D., An eddy-resolving numerical model of the ventilated thermocline, J. Phys. Oceanogr., 15, 1312-1324, 1985.

Dantzler, H.L., Jr., Potential energy maxima in the tropical and subtropical North Atlantic, J. Phys. Oceanogr., 7, 512-519, 1977.

Deser, C., and M.L. Blackmon, Surface climate variations over the North Atlantic ocean during winter: 1900-1989, J. Clim., 6, 1743-1753, 1993.

Dickinson, R.E., Convergence rate and stability of oceanatmosphere coupling schemes with a zero-dimensional climate model, J. Atmos. Sci., 38, 2112-2120, 1981.

Emery, W.J., On the geographic variability of the upper level mean and eddy fields in the North Atlantic and North Pacific, J. Phys. Oceanogr., 13, 269-291, 1983.

Emery, W.J., C.C. Ebbesmeyer, and J.P. Dugan, The fraction of the vertical isotherm deflections associated with eddies: An estimate from multiship XBT surveys, J. Phys. Oceanogr., 10, 885-899, 1980.

Ezer, T., and G.L. Mellor, A numerical study of the variability and the separation of the Gulf Stream, induced by surface atmospheric forcing and lateral boundary flows, $J$. Phys. Oceanogr., 22, 660-682, 1992.

Favorite, F., and D.R. McClain, Coherence in trans-Pacific movements of positive and negative anomalies of seasurface temperature 1953-1960, Nature, 244, 139-143, 1973.

Fu, L., T. Keffer, P.P. Niiler, and C. Wunsch, Observations of mesoscale variability in the western North Atlantic: A comparative study, J. Mar. Res., 40, 809-848, 1982.

Gough, W., and C.A. Lin, The response of an ocean general circulation model to long time scale surface anomalies. Atmos. Ocean, 30, 653-674, 1992.

Greatbatch, R.J., and S. Zhang, An interdecadal oscillation in an idealised ocean basin forced by constant heat flux, J. Clim., 8, 81-91, 1995.

Greatbatch, R.J., G. Li, and S. Zhang, Hindcasting ocean climate variability using time-dependent surface data to drive a model: An idealised study, J. Phys. Oceanogr., in press, 1995.

Han, Y.J., A numerical world ocean general circulation model, II A baroclinic experiment, Dyn. Atmos. Oceans, 8, 141-172, 1984 .

Haney, R.L., Surface thermal boundary condition for ocean circulation models, J. Phys. Oceanogr., 1, 241-248, 1971.

Holland, W. R., The role of mesoscale eddies in the general circulation of the ocean - numerical experiments using a wind-driven quasi-geostrophic model, J. Phys. Oceanogr., 8, 365-392, 1978.

Holland, W.R., and M.L. Batteen, The parameterization of sub-grid-scale heat diffusion in eddy-resolved ocean circulation models, J. Phys. Oceanogr., 16, 200-206, 1986.

Holland, W.R., and W.J. Schmitz, Zonal penetration scale of model midlatitude jets, J. Phys. Oceanogr., 15, 1859$1875,1985$.

Huang, R.X., Does atmospheric cooling drive the Gulf Stream recirculation?, J Phys. Oceanogr., 20, 750-757, 1990.

Le Traon, D.Y., M.C. Rouquet, and C. Boissier, Spatial scales of mesoscale variability in the North Atlantic as deduced from Geosat data, J. Geophys. Res., 95, 20,26720,285, 1990.

Levitus, S., Climatological atlas of the world ocean, NOAA Prof. Pap. 13, 173 pp., U.S. Govt. Print. Off., Washington, D.C., 1982

Liu, W.T., A. Zhang, and J.K.B. Bishop, Evaporation and 
solar irradiance as regulators of sea surface temperature in annual and interannual changes, J. Geophys. Res., 99, 12,623-12,637, 1994.

Marotzke, J., Ocean models in climate problems, in Ocean Processes in Climate Dynamics: Global and Mediterranean Examples, edited by P. Malanotte-Rizzoli and A.R. Robinson, Kluwer Academic, Norwell, Mass., 1994.

Pedlosky, J., The development of thermal anomalies in a coupled ocean-atmosphere model, J. Atmos. Sci., 32, 1501-1514, 1975.

Rahmstorf, S., and J. Willebrand, The role of temperature feedback in stabilising the thermohaline circulation, $J$. Phys. Oceanogr., 25, 787-805, 1995.

Richardson, P.L., Eddy kinetic energy in the North Atlantic from surface drifters, J. Geophys. Res., 88, 4355-4367, 1983.

Robert, A., A stable numerical integration scheme for the imitive meteorological equations, Atmos. Ocean, 19, 3546, 1981.

Robinson, A.R., D.E. Harrison, Y. Mintz, and A.J. Semtner, Eddies and the general circulation of an idealized oceanic gyre: A wind and thermally driven primitive equation numerical experiment, J. Phys. Oceanogr., 7, 182-207, 1977.

Sadourny, R., The dynamics of finite-difference models of the shallow water equations, J. Atmos. Sci., 32, 680689,1975 .

Schopf, P.S., On the equatorial waves and El Nino, II, Effects of air-sea thermal coupling, J. Phys. Oceanogr., 13, 1878$1893,1983$.

Semtner, A.J., and R.M. Chervin, A simulation of the global ocean circulation with resolved eddies, J. Geophys. Res., 93, 15,502-15,522, 1988.

Semtner, A.J., and R.M. Chervin, Ocean general circulation from a global eddy-resolving model, J. Geophys. Res., 97, 5493-5550, 1992.

Semtner, A.J., and Y. Mintz, Numerical simulation of the Gulf Stream and mid-ocean eddies, J. Phys, Oceanogr., 7, 208- 230, 1977.

Spall, M.A., Circulation in the Canary Basin: A model/data analysis, J. Geophys. Res., 95, 9611-9628, 1990.
Stammer D., and C.W. Boning, Mesoscale variability in the Atlantic Ocean from Geosat altimetry and WOCE highresolution numerical modeling, J. Phys. Oceanogr., 22, 732-752, 1992.

Treguier, A.M., Kinetic energy analysis of an eddy resolving, primitive equation model of the North Atlantic Ocean, $J$. Geophys. Res., 97, 687-701, 1992.

Wunsch, C., Low-frequency variability of the sea, in Evolution of Physical Oceanography, edited by B. A. Warren and C. Wunsch C., chap. 11, pp. 342-374, MIT Press, Cambridge, Mass., 1981.

Wunsch, C., Western North Atlantic interior, in Eddies in Marine Sciences, edited by A. R. Robinson, pp. 4664, Springer-Verlag, New York, 1983.

Wyrtki, K., L. Magaard, and J. Hager, Eddy energy in the oceans, J. Geophys. Res., 81, 2641-2646, 1976.

$\mathrm{Xu}, \mathrm{W}$., A C-grid ocean general circulation model and eddy simulation, Ph.D. thesis, McGill Univ., Montreal, Que., 1994.

$\mathrm{Xu}, \mathrm{W}$,, and C.A. Lin, A numerical solution of the linear Rayleigh-Bénard convection equations with B- and C-grid formulations, Tellus, Ser. A, 45, 193-200, 1993.

Zhang, S., R.J. Greatbatch, and C.A. Lin, A re-examination of the polar halocline catastrophe and implications for coupled ocean-atmosphere models, J. Phys. Oceanogr., 23, 287-299, 1993.

R. J. Greatbatch, Department of Physics, Memorial University of Newfoundland, St. John's, Newfoundland, Canada A1B 3X7 (email: rgreat@crosby.physics.mun.ca).

C. A. Lin, Department of Atmospheric and Oceanic Sciences and Center for Climate and Global Change Research, McGill University, 805 Sherbrooke Street West, Montreal, Quebec, Canada H3A 2K6 (email: lin@cerca.umontreal.ca).

W. Xu, Climate Research Division, Scripps Institute of Oceanography, 9500 Gilman Drive, La Jolla, CA 92036-0224 (email: weimin@cayman.ucsd.edu).

(Received August 26, 1994; revised April 21, 1995; accepted May 22, 1995.) 